\title{
Long term effects of exposure to viral infections in utero
}

\author{
P E M FINE, A M ADELSTEIN, J SNOWMAN, J A CLARKSON, S M EVANS
}

\begin{abstract}
An analysis was conducted of the major findings of a long term follow up study of 3076 subjects who were exposed to viral infections in utero and who at the time of analysis were up to 40 years of age. Mortality and morbidity were compared with those in a control population matched for sex and date and area of birth. An excess of cancers (16 cases against seven) appeared to be clustered among those exposed to herpes viruses (varicella or cytomegalovirus). There was evidence of an increased risk of diabetes among those exposed to mumps during the first trimester (four cases among 128 subjects against none in 148 controls). The most surprising finding was a decrease of diseases of the skin and subcutaneous tissue and of the nervous system among subjects exposed to antenatal varicella zoster infection.
\end{abstract}

The mechanism for the association may include production of fetal anti-idiotype antibodies in response to transplacentally acquired maternal autoantibodies.

\section{Introduction}

Ever since the report by Gregg, in 1941, of an association between congenital cataracts and antenatal exposure to rubella there has several years. Firstly, antenatal rubella or cytomegalovirus infections lead to impaired hearing, speech defects, mental retardation, learning difficulties, and behavioural problems ${ }^{2}$; secondly, there is an increased risk of diabetes among children exposed to antenatal rubella ${ }^{5}$; thirdly, there is conflicting evidence linking antenatal viral infection and subsequent malignant disease. ${ }^{6-14}$

Such long term effects of antenatal infection have proved difficult to investigate because of an absence of appropriate study populations. This paper presents the major findings of a long term follow up study based on records of 3076 subjects exposed to antenatal viral infection and who at the time of analysis were up to 40 years of age. A full report of the investigation will be published elsewhere. ${ }^{15}$

\section{Methods}

Of the 3076 subjects, 877 had been identified originally as part of a major prospective investigation begun in 1950-the "Manson study" -of the association between viral infection and congenital abnormalities. ${ }^{16-18}$ The initial ascertainment of these subjects had been unbiased in so far as they were recruited into the original study only if the report of their antenatal exposure to viral infection was received at the General Register Office before their date of birth. Unfortunately, the records of those with congenital disease recognised by 2 years of age were lost.

\begin{tabular}{|c|c|c|c|c|c|c|}
\hline \multirow{2}{*}{$\begin{array}{l}\text { Antenatal viral } \\
\text { "infection" exposure }\end{array}$} & \multirow{2}{*}{$\begin{array}{l}\text { Original Manson } \\
\text { study recruitment }\end{array}$} & \multicolumn{2}{|c|}{ Adelstein-Donovan study recruitment } & \multicolumn{2}{|c|}{ Additional recruitment (this study) } & \multirow{2}{*}{ Total } \\
\hline & & Unbiased & Biased & Unbiased & Biased & \\
\hline Influenza & - & 555 & 26 & - & - & 581 \\
\hline Varicella & 252 & 63 & 30 & - & 1 & 346 \\
\hline Herpes zoster & - & 61 & 18 & - & - & 79 \\
\hline Mumps & 417 & 84 & 24 & - & - & 525 \\
\hline Rubella & 205 & 221 & 357 & - & - & 783 \\
\hline Measles & 3 & 40 & 4 & - & - & 47 \\
\hline Hepatitis & - & 192 & 51 & - & - & 243 \\
\hline Cytomegalovirus & - & - & 1 & 27 & 69 & 97 \\
\hline Miscellaneous viruses & - & 230 & 25 & - & - & 255 \\
\hline Multiple sclerosis & - & 84 & 20 & 二 & - & 104 \\
\hline Hodgkin's disease & 二 & $\underline{-1}$ & 16 & - & - & 16 \\
\hline Total & 877 & 1530 & 572 & 27 & 70 & 3076 \\
\hline
\end{tabular}

been an increasing appreciation that viral infections during pregnancy may be deleterious to the fetus or offspring. ${ }^{1-3}$ Though most of the effects of antenatal viral infection so far documented are recognisable at or shortly after birth, associations have also been reported between antenatal viral infections and three conditions which arise or become recognisable only after

Ross Institute, London School of Hygiene and Tropical Medicine, London WC1E 7HT

P E M FINE, VMD, PHD, senior lecturer

J SNOWMAN, BA, research fellow

J A CLARKSON, ARCS, MSC, research fellow

Division of Medical Statistics and Epidemiology, London School of Hygiene and Tropical Medicine, London WC1E 7HT

A M ADELSTEIN, MD, FRCP, honorary professor of epidemiology

$S$ M EVANS, BA, MSC, research fellow

Correspondence to: Dr P E M Fine.
Thus we have a sample which is in one sense selectively "healthy" compared with all subjects exposed to antenatal viral infection.

A further 2102 subjects were part of a study of antenatal viral infection and cancer carried out at the Office of Population Censuses and Surveys. ${ }^{19}$ We divided their sources into those in which the original ascertainment could be considered unbiased and those which could be biased, in that the ascertainment may have been sometimes influenced by the presence of congenital or childhood disease (table I).

The remaining 97 exposed subjects were identified for this study by Professor H Stern and Dr H Macdonald.

An attempt was made to trace the name of the general practitioner of each exposed subject by means of the National Health Service Central Register and local family practitioner committees. In addition, for each exposed subject the NHS Central Register selected a control matched for sex and date and area of birth. Copies of death certificates were obtained for all those recorded as deceased in the register. A one page questionnaire was sent to general practitioners in order to obtain information on the health of each living subject.

The research design was approved by the Central Ethical Committee of the BMA. Other details concerning ascertainment of cases, selection of controls, tracing, content of questionnaire, coding, procedures of analysis, and general results are given in the full report. ${ }^{15}$ 


\section{Results}

Follow up information (either a death certificate or a completed questionnaire) was obtained for $2570(84 \%)$ of the exposed subjects and $2475(80 \%)$ of the controls. We report three of the more important findings.

\section{CANCER}

Malignant disease (ICD codes (9th revision) 140-208; 230-234; 630 ) was reported in 16 of the exposed subjects, including eight deaths, and seven of the controls, including three deaths (table II). The overall excess incidence of cancer in the exposed population was of borderline subcutaneous tissue (ICD, chapter II) were reported in subjects exposed to varicella zoster infection in utero (three cases of contact dermatitis) than in their matched controls (24 subjects with eigh diagnoses of contact dermatitis; three of psoriasis; two of atopic dermatitis; and single diagnoses of erythema nodosum; pityriasis rosea; circumscribed scleroderma; keratoderma; acne; disorder of skin; lipoma; benign neoplasms of eyelid, skin of face, and skin of trunk; haemangioma; and lymphangioma (one subject had two diagnoses)). Though this difference is statistically highly significant ( $\chi^{2}$ test $=17.0 ; p<0.0001$ ), we must examine it with caution.

Several lines of evidence suggest that this finding is not just a statistical fluke. Firstly, statistically significant negative associations between antenatal exposure to virus and subsequent disease classified within ICD chapter XII arose twice-for subjects exposed to chickenpox in

TABLE II-Malignant disease (ICD codes (9th revision) 140-208), carcinoma in situ (230-234), and hydatidiform mole (630) in subjects exposed to viral infections in utero and in controls

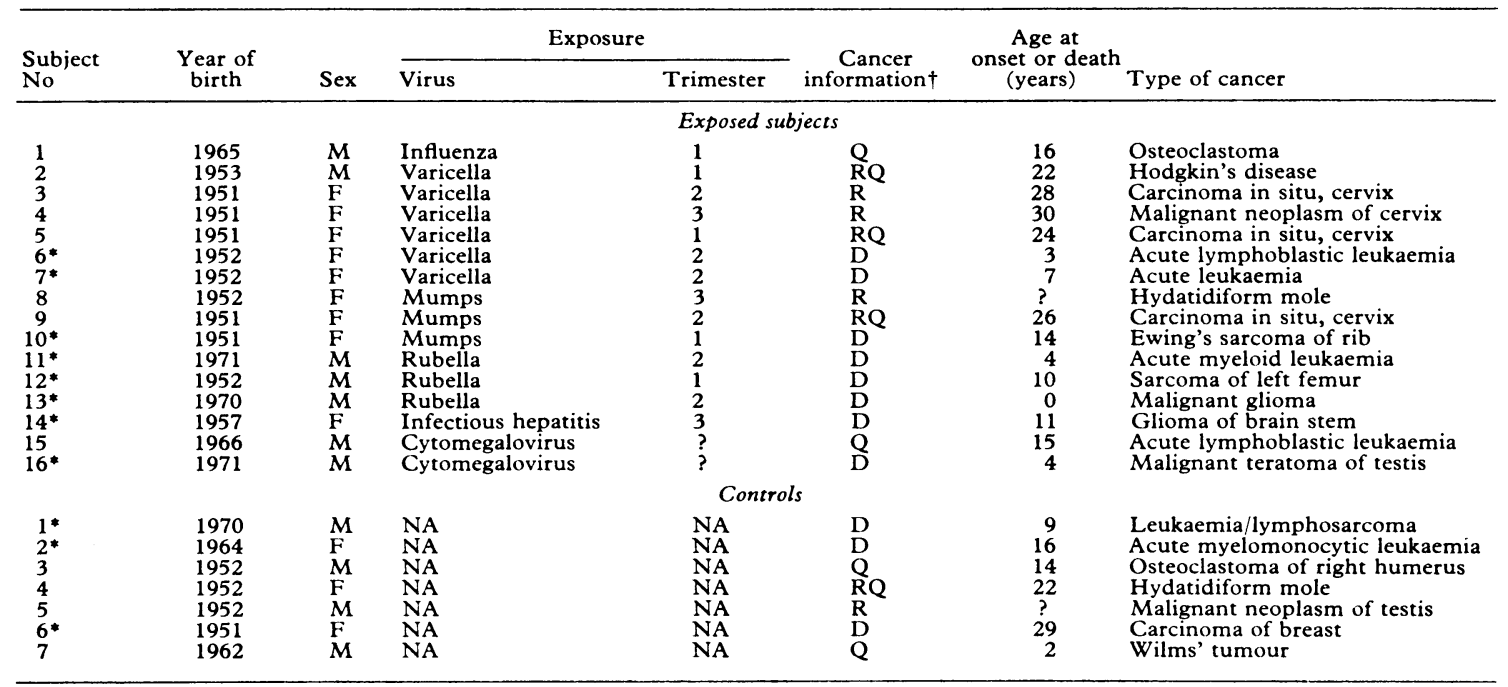

NA $=$ Not applicable

† Dead.

statistical significance (standard normal deviate $(\mathrm{SND})=1.67$ by McNemar's test; $p<0.05$ by one tailed test only). Inspection of the data suggested a possible clustering of cancer risk among subjects exposed to chickenpox in the original study of Manson (six out of 252) compared with their matched controls (one out of 252) (SND = 1.51 by McNemar's test; $p=0.06$ by a one tailed comparison). The six cancers among exposed subjects included two fatal leukaemias, one Hodgkin's disease, one malignant neoplasm of the cervix, and two cervical carcinomas in situ. Two cancers (one lymphoblastic leukaemia and one malignant teratoma of the testis) were reported among the 97 subjects exposed in utero to cytomegalovirus.

\section{DIABETES}

Only two cases of diabetes were reported among 616 subjects exposed to antenatal rubella, and three cases among 605 controls.

Inspection of reports of diabetes among our exposed population disclosed a cluster of four cases among 431 subjects exposed to mumps. All of these were among 128 subjects exposed during the first trimester of pregnancy, and all were in the original study of Manson. Their diabetes was diagnosed between the ages of 13 and 21 . Though this excess does not reach formal statistical significance (four out of 128 versus none of 148 controls; $p=0.09$ by two tailed Fisher's exact test), we note below several reasons why this may reflect a real biological phenomenon.

DEFICIT OF DISEASE OF SKIN AND NERVOUS TISSUE AMONG SUBJECTS EXPOSED TO VARICELLA ZOSTER

Considerably less disease of the skin and subcutaneous tissue (ICD (9th revision), chapter $\mathrm{XII}$ ) and fewer neoplasms of the skin and the original series of Manson and for subjects exposed to zoster in the subsequent unbiased recruitment series. That chickenpox and zoster represent two different manifestations of the same (herpes varicella zoster) viral infection in mothers and that these ascertainment groups were totally separate and independent lend credence to the association. Secondly, the other groups in this investigation exposed to chickenpox and zoster were small, but deficits of diagnoses listed in ICD chapter XII were noted in each of them. ${ }^{15}$ Thirdly, associations between antenatal viral infection and benign neoplasms arose only once in the entire study. This was also a negative association and was restricted to benign neoplasms of the skin and subcutaneous tissue (ICD, chapter II) among people exposed to varicella or zoster (no cases among exposed subjects compared with six among controls). This difference is itself statistically significant ( $p=0.02$ by two sided Fisher's exact test). Fourthly, the deficit of diagnoses listed in ICD chapter XII among subjects exposed to varicella zoster virus was significant $\left(\chi^{2}=\right.$ $6.2 ; p=0.01$ ) when compared with all other exposed and contro groups together.

Finally, it may be relevant that the incidence of disorders of the nervous system (ICD, chapter VIA) was significantly lower among subjects exposed to antenatal chickenpox in Manson's series than among their controls (none out of 197 against seven out of $187 ; \mathrm{p}=$ 0.01 by Fisher's exact test). This may reflect a chance finding or it may reflect the selective removal of children severely ill before the age of 2 from this exposed group. On the other hand, there are biological similarities between nervous tissue and skin (both are ectoderm in origin) and both these tissues are selectively invaded by the varicella zoste virus.

\section{Discussion}

An excess of malignant disease was found among exposed subjects (16 cases, eight deaths) compared with controls (seven 
cases, three deaths). This finding is consistent with several reports suggesting an increase of malignant disease associated with antenatal exposure to viral infections. The increased risk observed in this study appeared to be restricted to people exposed to chickenpox and perhaps also to cytomegalovirus. Though malignant disease has been linked with antenatal exposure to chickenpox, 7121321 our finding of two cancers among 97 subjects exposed to cytomegalovirus was unexpected, as we are not aware of any reports linking antenatal cytomegalovirus with malignant disease. It may be relevant that both varicella zoster and cytomegalovirus belong to the herpes group, as herpes viruses have long been considered prime candidates for carcinogenic potential. ${ }^{21}{ }^{22}$ There was no evidence that risk of cancer was associated with trimester of antenatal exposure. Aside from chickenpox, the antenatal viral infection most often discussed as a possible cause of cancer is influenza. Our investigation disclosed only a single cancer among 581 exposed subjects, thus providing no evidence for such an association.

Our findings provide no support for claims of an increase of diabetes among subjects exposed to antenatal rubella. ${ }^{5}$ Most published reports relate to studies of subjects with frank congenital rubella syndrome, whereas such people were selectively absent from our main group exposed to rubella (Manson's series). Thus our results suggest that the risk of diabetes among all subjects exposed to antenatal rubella is not very great.

In contrast with the absence of evidence linking diabetes with antenatal rubella in our data, we found a suspicious cluster of four cases of diabetes among 128 subjects exposed to maternal mumps during the first trimester. Though this association has not been reported before, and it does not reach statistical significance, it may be real. There is strong evidence for an association between childhood mumps and acute onset of diabetes within weeks or months thereafter, ${ }^{23-25}$ and mumps virus may grow in cells of the human pancreas. ${ }^{26}$ The reported association between congenital rubella and subsequent diabetes ${ }^{5}$ provides a precedent that antenatal exposure to this virus may cause diabetes many years later. That Manson's series did not include subjects with congenital illness diagnosed before 2 years of age suggests that ours may be an underestimate of the risk among all subjects exposed to mumps in the first trimester. None the less, finding four diabetics among 128 exposed subjects $(3 \%)$ indicates in itself a prevalence of diabetes roughly 15 times that reported at age 30 in the population of Britain. ${ }^{27}$

The most surprising finding in our study is the evidence that people exposed to varicella zoster virus in pregnancy experience appreciably less disease of skin and subcutaneous tissue, and perhaps also disease of the nervous system, than do unexposed controls (or than do subjects exposed to other antenatal viral infections). We cannot explain away the associations as an artefact of sampling or social class. That varicella and zosterthough recorded separately-are in fact the same virus, and that the negative association relates to the two tissues (skin and nervous system) selectively invaded by this virus, enhance the evidence that the association is real.

We have tried to find a biological mechanism for this association. Many of the conditions which appeared to be selectively absent from the exposed group probably included some form of local immune dysfunction or local autoimmune process. Absence of this pathological process would suggest a specific tolerance in these subjects (specific because we found no evidence for a deficit of other immunological disorders or allergies among the group exposed to varicella zoster). This could be mediated by anti-idiotype antibodies produced in the fetus to transplacentally transmitted autoantibodies produced in the mother in response to her acute infection. Such autoantibodies occur in some herpes infections-for example, cytomegalovirus ${ }^{28}$ - and anti-idiotype antibodies produced against them would carry determinants homologous to the altered membranes of the virus infected maternal skin or nerve cells. There are several diseases known to be mediated by transplacentally acquired maternal antibody-for example, haemolytic disease of the newborn and neonatal thyrotoxicosis attributable to transplacentally acquired long acting thyroid stimulator. ${ }^{29}$ On the other hand, we are not aware of published evidence that a fetus may produce antiidiotype antibodies to maternal antibody or that maternal antibody can lead to disease many years later. Though speculative, this mechanism is at least suggestive of processes which would be extremely difficult to detect except through such a study population as ours. And it reinforces our conclusion that there is still much to be learnt concerning the long term effects of exposure to viral infections in utero.

This investigation was made possible by a grant from the Department of Health and Social Security. Professor Adelstein's work was supported by the Cancer Research Campaign. We thank the staffs of the Office of Population Censuses and Surveys, NHS Central Register, and family practitioner committees. Special thanks are due to the many family practitioners who provided information on their patients.

\section{References}

1 Gregg NM. Congenital cataract following German measles in the mother. Transactions of the Ophthalmological Society of Australia 1941;3:35-46.

In: 489-514.

3 Peckham CS, Marshall WC. Infections in pregnancy. In: Obstetrical epidemiology. London: Academic Press, 1983:209-62

4 Menser MA, Forrest JM. Rubella-high incidence of defects in children considered normal at birth. Med f Aust 1974;i:123-6.

5 Menser MA, Forrest JM, Bransby RD. Rubella infection and diabetes mellitus. Lancet $1978 ; \mathrm{i}: 57-60$.

6 Fedrick J, Alberman ED. Reported influenza in pregnancy and subsequent cancer in the child. Br Med $\mathcal{F} 1972 ; 1: 485-8$.

7 Adelstein AM, Donovan JW. Malignant disease in children whose mothers had chickenpox, mumps, or rubella in pregnancy. $\mathrm{Br}$ Med $\mathcal{F} 1972$;iv:629-31.

8 Hakulinen T, Hovi L, Karkinen-Jaaskelainen M, Penttinen K, Saxen L. Association between influenza during pregnancy and childhood leukaemia. $\mathrm{Br}$ Med $\mathcal{f}$ 1973 ; iv: $265-7$

Leck I, Steward JK. Incidence of neoplasms in children born after influenza epidemics. Br Med F 1972;iv:631-4.

10 Curnen MGM, Varma AAO, Christine BW, Turgeon LR. Childhood leukaemia and maternal infectious diseases during pregnancy. FNCI 1974;53:943-7.

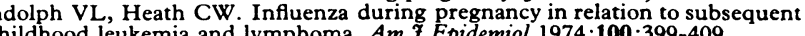
childhood leukemia and lymphoma. Am f Epidemiol 1974;100:399-409.

ithell JF, Draper GJ, Gorbach PD. Association between malignant disease in

13 Till M, Rapson N, Smith PG. Family studies in acute leukaemia in childhood: a possible association with autoimmune disease. Br $\mathcal{F}$ Cancer 1979;40:62-71.

14 Blot WJ, Draper G, Kinlen L, Wilson MK. Childhood cancer in relation to prenatal exposure to chickenpox. Br $\mathcal{f}$ Cancer 1980;42:342-4

15 Fine PEM, Adelstein AM, Snowman J, Clarkson JA, Evans SM. A follow-up study of the long term effects of exposure to viral infections in utero. London: Office of Population Censuses and Surveys (in press).

16 Manson MM, Logan WPD, Loy RM. Rubella and other virus infections during pregnancy. In: Reports on public health and medical subjects. No 101. London: HMSO, 1960

17 Jackson ADM, Fisch L. Deafness following maternal rubella. Results of a prospective investigation. Lancet $1958 \cdot \mathrm{ii}: 1241-4$

18 Sheridan MD. Final report of a prospective study of children whose mothers had

rubella in early pregnancy. Br Med $\mathcal{F} 1964$;ii :536-9.
19 Adelstein AM, Donovan JW, Leighton PC, Pike MC. Sequelae of virus infection in pregnancy. In: Child health: a collection of studies on medical and population subjects. No 31 . London: OPCS, HMSO, 1976.

20 Vianna NJ, Polan AK. Childhood lymphatic leukemia: prenatal seasonality and possible association with congenital varicella. Am $\mathcal{F}$ Epidemiol 1976;103: 321-32.

21 Minson AC. Cell transformation and oncogenesis by herpes simplex virus and human cytomegalovirus. Cancer Surveys 1984;3:92-111.

22 Weiss RA. Viruses and human cancer. In: Mahy BWJ, Pattison JR, eds. The microbe 1984: part 1, viruses. Society for General Microbiology, Symposium 36 Cambridge: Cambridge University Press, 1984:211-40.

23 Gundersen E. Is diabetes of infectious origin? f Infect Dis 1927:41:197-202.

23 Gundersen E. Is diabetes of infectious origin? 7 Infect Dis $1927 ; 41: 197-202$. Nord Med 1958;60:1715-7.

25 Gamble DR. The epidemiology of insulin dependent diabetes with particular reference to the relationship of virus infection to its etiology. Epidemiol Rev 1980;2:49-70.

26 Prince GA, Jenson AB, Billups LC, Notkins AL. Infection of human pancreatic beta cell cultures with mumps virus. Nature 1978;271:158-61.

27 Royal College of General Practitioners, Office of Population Censuses and Surveys, Department of Health and Social Security. Morbidity statistics from general practice: 1970-2: second national study. London: OPCS, HMSO, 1974 1979. (Studies on Medical and Population Subjects, Nos 26, 36.

28 Kantor GL, Goldberg LF, Johnson BL, Derechin MM, Barnett EV. Immunologic abnormalities induced by post-perfusion cytomegalovirus infection. $A n n$ Intern Med 1970;73:553-8.

29 Scott JS. Immunological diseases and pregnancy. Br Med $\mathcal{F} 1966$;i:1559-67.

(Accepted 15 fanuary 1985) 